\title{
An Exploration of Catalytic Chemistry on $\mathrm{Au} / \mathrm{Ni}(111)$
}

DE-FG02-05ER15665

May 15, 2005 - February 14, 2010

Professor S. T. Ceyer

Department of Chemistry

Massachusetts Institute of Technology, Cambridge, MA 02139

stceyer@mit.edu

\section{PROJECT SCOPE}

This project explored the catalytic oxidation chemistry that can be effected on a $\mathrm{Au} / \mathrm{Ni}(111)$ surface alloy. A $\mathrm{Au} / \mathrm{Ni}(111)$ surface alloy is a Ni(111) surface on which less than $60 \%$ of the $\mathrm{Ni}$ atoms are replaced at random positions by Au atoms. The alloy is produced by vapor deposition of a small amount of Au onto Ni single crystals. The Au atoms do not result in an epitaxial Au overlayer or in the condensation of the Au into droplets. Instead, $\mathrm{Au}$ atoms displace and then replace $\mathrm{Ni}$ atoms on a $\mathrm{Ni}(111)$ surface, even though $\mathrm{Au}$ is immiscible in bulk Ni. The two dimensional structure of the clean $\mathrm{Ni}$ surface is preserved. This alloy is found to stabilize an adsorbed peroxo-like $\mathrm{O}_{2}$ species that is shown to be the critical reactant in the low temperature catalytic oxidation of $\mathrm{CO}$ and that is suspected to be the critical reactant in other oxidation reactions. This investigation revealed a new, practically important catalyst for $\mathrm{CO}$ oxidation that has since been patented.

\section{RESULTS}

\section{Nature of $\mathrm{O}_{2}$ and $\mathrm{O}$ Binding on Au/Ni Surface Alloy}

As part of our studies of the catalytic oxidation reactivity, we have carried out a detailed study of the interaction of $\mathrm{O}_{2}$ with the $\mathrm{Au} / \mathrm{Ni}(111)$ surface alloy. We find that the adsorption of $\mathrm{O}_{2}$ is molecular at $77 \mathrm{~K}$. This observation is in stark contrast to the adsorption of $\mathrm{O}_{2}$ on $\mathrm{Ni}(111)$, which is dissociative even at $8 \mathrm{~K}$. This observation is also in stark contrast to the interaction of $\mathrm{O}_{2}$ with $\mathrm{Au}(111)$ because $\mathrm{O}_{2}$ adsorbs neither molecularly nor dissociatively on $\mathrm{Au}(111)$ at or above $100 \mathrm{~K}$. The addition of a small amount of $\mathrm{Au}$ to Ni lowers the Fermi level so that the overlap of the Ni 3d electrons with the $\pi^{*}$ orbitals of $\mathrm{O}_{2}$ is less than what it is on pure Ni. It is just enough less to stabilize $\mathrm{O}_{2}$ from dissociation on the $\mathrm{Au} / \mathrm{Ni}$ surface alloy but not so little as to preclude adsorption as on $\mathrm{Au}(111)$. Molecularly adsorbed $\mathrm{O}_{2}$ on $\mathrm{Au} / \mathrm{Ni}(111)$ is characterized by three distinct vibrational frequencies, $741 \mathrm{~cm}^{-1}, 852 \mathrm{~cm}^{-1}$ and $963 \mathrm{~cm}^{-1}$, as measured by high resolution electron energy loss spectroscopy, and are assigned to the vibration of the $\mathrm{O}=\mathrm{O}$ bond of molecular oxygen adsorbed on the alloy with its bond axis largely parallel to the surface. Molecular oxygen so adsorbed is considered a peroxo $\left(\mathrm{O}_{2}^{-2}\right)$ or superoxo $\left(\mathrm{O}_{2}{ }^{-1}\right)$ 
species. The three distinct $\mathrm{O}_{2}$ vibrational frequencies reflect three distinct binding sites, where the vibrational frequency is inversely proportional to the binding energy. The three sites are populated sequentially as a function of Au coverage. The more strongly bound $\mathrm{O}_{2}$, characterized by the lowest vibrational frequency of $741 \mathrm{~cm}^{-1}$, is stabilized on the $\mathrm{Au} / \mathrm{Ni}$ surface alloy at a low Au coverage, $0.25 \mathrm{ML}$. At 0.3 ML Au, a feature at 852 $\mathrm{cm}^{-1}$ and a feature at $963 \mathrm{~cm}^{-1}$ appear. The three features grow in intensity until a maximum intensity of the $741 \mathrm{~cm}^{-1}$ feature is achieved at about $0.38 \mathrm{ML} \mathrm{Au}$ and a maximum intensity of the $852 \mathrm{~cm}^{-1}$ and $963 \mathrm{~cm}^{-1}$ features is achieved at about $0.45 \mathrm{ML}$ $\mathrm{Au}$. The intensity of all features then decreases as the Au coverage is increased and approaches zero at about $0.65 \mathrm{ML} \mathrm{Au}$. The frequency of the $963 \mathrm{~cm}^{-1}$ feature shifts up to about $1000 \mathrm{~cm}^{-1}$ as the Au coverage increases from $0.45 \mathrm{ML}$ to $0.65 \mathrm{ML}$.

A Monte Carlo simulation of the molecular $\mathrm{O}_{2}$ coverage as a function of $\mathrm{Au}$ coverage was carried out to probe the site requirements for $\mathrm{O}_{2}$ adsorption. The best agreement between the simulated and experimental $\mathrm{O}_{2}$ coverage is observed when $\mathrm{O}_{2}$ sits in a $\mathrm{Ni}$ atom bridge site of an ensemble of $6 \mathrm{Ni}$ and $4 \mathrm{Au}$ atoms of any hexagonal configuration. Molecular adsorption is blocked when an adsorbed $\mathrm{O}$ atom is within $5 \AA$ of the bridge site. These high resolution vibrational spectra of molecularly adsorbed $\mathrm{O}_{2}$ on the $\mathrm{Au} / \mathrm{Ni}(111)$ surface alloy will serve as important benchmarks for the continued development of density functional theory for surface adsorbates.

The peroxo and superoxo species dissociate after heating the surface to $105-120 \mathrm{~K}$ as evidenced by the disappearance of their $\mathrm{O}=\mathrm{O}$ stretch modes and the appearance of two features at 580 and $435 \mathrm{~cm}^{-1}$, attributed to atomically adsorbed $\mathrm{O}$. These features at 580 $\mathrm{cm}^{-1}$ and $435 \mathrm{~cm}^{-1}$ have the same frequency as observed for $\mathrm{O}$ atoms bound to $\mathrm{Ni}(111)$. Extensive detailed measurements have shown that about $10 \%$ of the $\mathrm{O}_{2}$ does not dissociate but rather desorbs molecularly between 105-120 K.

\section{Catalytic Oxidation of CO on a Au/Ni Surface Alloy}

We have discovered that the peroxo and superoxo species stabilized on the $\mathrm{Au} / \mathrm{Ni}(111)$ surface alloy efficiently oxidize $\mathrm{CO}$ at $70 \mathrm{~K}$. The experiment is carried out in the following manner. Saturation coverage of molecular $\mathrm{O}_{2}$ is adsorbed on the $0.44 \mathrm{ML}$ $\mathrm{Au} / \mathrm{Ni}$ surface alloy at $77 \mathrm{~K}$. When a beam of thermal energy $\mathrm{CO}$ is directed at the $\mathrm{O}_{2}$ covered $\mathrm{Au} / \mathrm{Ni}(111)$ surface alloy held at $70 \mathrm{~K}$, gas phase $\mathrm{CO}_{2}$ is immediately produced. A control experiment demonstrates that no $\mathrm{CO}_{2}$ is produced when the $\mathrm{CO}$ beam impinges on the crystal mount.

After exposure of the $\mathrm{O}_{2}$-covered surface alloy at $70 \mathrm{~K}$ to $\mathrm{CO}$, two $\mathrm{C}=\mathrm{O}$ stretch vibrational modes are observed at 2170 and $2110 \mathrm{~cm}^{-1}$, along with the Au/Ni-CO stretch mode at $420 \mathrm{~cm}^{-1}$. The $\mathrm{O}=\mathrm{O}$ modes at $852 \mathrm{~cm}^{-1}$ and $963 \mathrm{~cm}^{-1}$ are much reduced in 
intensity, while the feature at $741 \mathrm{~cm}^{-1}$ has maintained its intensity. The decrease in intensities of the $852 \mathrm{~cm}^{-1}$ and $963 \mathrm{~cm}^{-1}$ features is interpreted to mean that most of the molecularly adsorbed $\mathrm{O}_{2}$ has reacted with $\mathrm{CO}$ to form gas phase $\mathrm{CO}_{2}$. The product remaining from this reaction is an $\mathrm{O}$ atom adsorbed to $\mathrm{Au}$, as evidenced by the appearance of a new feature at $660 \mathrm{~cm}^{-1}$. The molecularly adsorbed $\mathrm{O}_{2}$ that gives rise to the feature at $741 \mathrm{~cm}^{-1}$ appears not to react with $\mathrm{CO}$.

This alloy surface covered with $\mathrm{CO}$ and some adsorbed $\mathrm{O}_{2}$ is heated at $2 \mathrm{~K} / \mathrm{s}$ while the partial pressures at masses 44 and 28 are monitored. Rapid production and desorption of $\mathrm{CO}_{2}$ is clearly observed between 105-120 K, along with $\mathrm{CO}$ desorption. Production of $\mathrm{CO}_{2}$ in this temperature range occurs at the same temperature at which $\mathrm{O}_{2}$ dissociates. This observation suggests that $\mathrm{CO}_{2}$ formation occurs between $\mathrm{CO}$ and a "hot" $\mathrm{O}$ atom that has not yet equilibrated with the surface after bond dissociation. From $120 \mathrm{~K}$ to about $250 \mathrm{~K}, \mathrm{CO}_{2}$ is slowly produced by reaction of the adsorbed $\mathrm{O}$ atoms represented by $660 \mathrm{~cm}^{-1}$ mode and by the adsorbed $\mathrm{O}$ atoms that did not react immediately as a hot $\mathrm{O}$ atom upon $\mathrm{O}_{2}$ dissociation.

Additional measurements of the $\mathrm{CO}_{2}$ production at $77 \mathrm{~K}$ as a function of $\mathrm{Au}$ coverage show that $\mathrm{CO}_{2}$ production correlates with molecular $\mathrm{O}_{2}$ coverage (as measured by the intensity of the adsorbed peroxo species at 963 and $852 \mathrm{~cm}^{-1}$ ), where the maximum $\mathrm{CO}_{2}$ production and molecular $\mathrm{O}_{2}$ coverage occurs at $0.44 \mathrm{ML} \mathrm{Au}$.

These results demonstrate that $\mathrm{Au} / \mathrm{Ni}(111)$ catalyzes the oxidation of $\mathrm{CO}$ at low temperature. A US patent has been awarded for the development and discovery of this catalyst. Clearly, substitution of a small number of $\mathrm{Ni}$ atoms on the $\mathrm{Ni}(111)$ surface by $\mathrm{Au}$ atoms has dramatically changed the $\mathrm{Ni}$ chemistry. The oxidation of $\mathrm{CO}$ on $\mathrm{Ni}$ has never been observed under UHV laboratory conditions, presumably because both the oxygen atom and $\mathrm{CO}$ are too strongly bound, and hence the barrier to their reaction is too large. Introduction of $\mathrm{Au}$ into the $\mathrm{Ni}$ lattice serves to weaken the bonds between oxygen and $\mathrm{CO}$ so as to allow the reaction to proceed. These results also imply that nanosize $\mathrm{Au}$ clusters are not a necessary requirement for low temperature $\mathrm{CO}$ oxidation in general. Rather, interaction of the Au atoms around the perimeter of the Au nanocluster with the transition metal of the oxide support likely provides the active sites that stabilize the adsorption of molecular $\mathrm{O}_{2}$ that is necessary for the oxidation of $\mathrm{CO}$. 


\section{PATENT}

This investigation has resulted in an award of US patent No. 7,829,035 B2 on November 9, 2010 that is entitled Oxidation Catalyst to D. L. Lahr and S. T. Ceyer.

\section{PUBLICATIONS}

Catalyzed CO Oxidation at $70 \mathrm{~K}$ on an Extended Au/Ni Surface Alloy

D. L. Lahr and S. T. Ceyer, J. Am. Chem. Soc. 128, 1800 (2006)

Stabilization of Molecular $\mathrm{O}_{2}$ Adsorbed on a Au-Ni Surface Alloy

C. C. Leon, J. G. Lee, and S. T. Ceyer, in preparation, to be submitted to J. Phys Chem.

$\mathrm{O}_{2}$ Dissociation on $\mathrm{Au} / \mathrm{Ni}(111)$

C. C. Leon, J. G. Lee, and S. T. Ceyer, in preparation, to be submitted to J. Phys Chem.

Oxidation of $\mathrm{CO}$ on a Au/Ni Surface Alloy

J. G. Lee, D. L. Lahr, J. D. Fischer, C. C. Leon and S. T. Ceyer, in preparation, to be submitted to J. Phys Chem.

Absolute Calibration of Au Coverage on Ni

C. C. Leon and S. T. Ceyer, in preparation

\section{PH.D. THESES}

Molecular Oxygen Adsorbates at a Au/Ni(111) Surface Alloy and Their Role in Catalytic CO Oxidation at $70-250 \mathrm{~K}$, D. L. Lahr - June, 2006 - MIT

Adsorption of Molecular Oxygen on a Au/Ni(111) Alloy Surface and Its Oxidation of Co at $85 \mathrm{~K}$, J. D. Fischer - September, 2010 - MIT

Catalytic Activity of Au/Ni Surface Alloys, C. C. Leon - expected June, 2012 - MIT 